\title{
ЗАКОНОМЕРНОСТИ КОНДЕНСАЦИИ РЕЗОРЦИНА И ЕГО АЛКИЛЬНЫХ ПРОИЗВОДНЫХ С ФОРМАЛИНОМ В СПИРТОВОЙ СРЕДЕ
}

\author{
(Представил Н. Клесмент)
}

В производстве шин высокая прочность связи на границе волокнорезина достигается пропиткой синтетических вискозных и капроновых кордовых материалов специальными водными составами. Помимо водорастворимой резорцинформальдегидной смолы СФ-282, для этих целей широко используется смола СФ-280 (бывшая марка ФР-50А), изготовляемая на основе резорцина и фракции сланцевых алкилрезорцинов с пределами кипения $273-305^{\circ} \mathrm{C}$ (алкирез-1) в соотношении $1: 1^{[1,2}$. По адгезионным свойствам пропиточные составы на основе обеих смол равноценны. Однако при синтезе СФ-280 в промышленности, в частности на сланцехимическом заводе «Кивиыли», не решены вопросы выбора катализатора, имеются трудности в обеспечении стабильности и постоянства свойств смолы, мало изучена ее химическая структура.

Целью данной работы являлось исследование влияния условий конденсации на структуру СФ-280 методом спектроскопии ЯМР ${ }^{13} \mathrm{C}$. Все эксперименты были максимально приближены к производственным условиям ее изготовления.

Конденсацию смеси резорцина и алкилрезорцинов (соотношение 1:1) с формалином проводили в присутствии катализатора (уксусной кислоты, ацетата цинка). Мольное отношение фенольного сырья к формальдегиду составляло $1: 0,56$. К раствору резорцина и алкилрезорцинов в этаноле и этиленгликоле при $60-70{ }^{\circ} \mathrm{C}$ за $1-2$ ч постепенно добавляли $37 \%$-ный водный раствор формалина, в течение 3 ч реакционную массу доводили до кипения, затем выдерживали при температуре кипения 15 мин и охлаждали 4 ч до $30^{\circ} \mathrm{C}$. К охлажденной реакционной массе добавляли $20 \%$-ный раствор гидроокиси натрия из расчета 0,075 моля на 1 моль фенольного сырья и перемешивали 30 мин.

Полученные смолы анализировали методом ЯМР ${ }^{13} \mathrm{C}$ на спектрометре FT-80A фирмы «Varian» (США) на частоте 20 МГц. Для внутренней стабилизации в реакционную массу добавляли небольшое количество бензола Д-6. Пересчет химических сдвигов относительно ТМС производили по сигналам этилового спирта.

Для наглядности анализа спектров ЯМР ${ }^{13} \mathrm{C}$ полученных смол сначала рассмотрим спектры резорцина и 4-гексилрезорцина (рис. $1,1,2)$. Видно, что алкильный заместитель в положении 4 смещает сигналы углеродов при кислороде в более сильное поле примерно на 2 м. д. (область 150-160 м.д.), причем в случае 4-гексилрезорцина интенсивности линий углеродов в положениях 2 и 6 (рис. 1,2$)$ равны, а в случае резорцина различаются в два раза (область 100-110 м.д.), так как на сигнал углерода в положении 6 накладывается сигнал углерода в положении 4. Поэтому о степени превращения резорцина и 5 -алкилрезорцинов можно судить по соотношению сигналов в области $100-110$ м.д.

Смола, полученная по вышеописанной методике, на основе чистого 
резорцина (рис. 1,3 ) имеет группы сиг̄налов в области 160-150 м.д., которые отвечают непрореагировавшему резорцину, ди-, три- и тетрамерам [3]. Сигнал около 120 м.д. соответствует замещенному углероду ароматического кольца в положении 4 или 6 аналогично 4-гексилрезорцину (рис. 1,2$)$. Смола же на основе чистого резорцина, полученная ${ }^{3}$ водной среде, в присутствии уксусной кислоты (рис. 1,4), практически не имеет свободного резорцина, на что указывает равенство интенсивностей линий в области 100-110 м. д. Алкилрезорцины (алкирез-1) в аналогичных условиях реагирует с формалином с образованием высокомолекулярного продукта, нерастворимого в воде.

Сравнивая спектры ЯМР ${ }^{13} \mathrm{C}$ смол, которые синтезированы из смеси резорцина и алкилрезорцинов по вышеописанной методике в присутствии уксусной кислоты (рис. 1,5$)$ и ацетата цинка (рис. 1,6$)$, и смол, полученных на основе чистого резорцина (без катализатора), можно заключить, что катализатор и среда не оказывают существенного влияния на направление конденсации, хотя изменяют ее скорость.

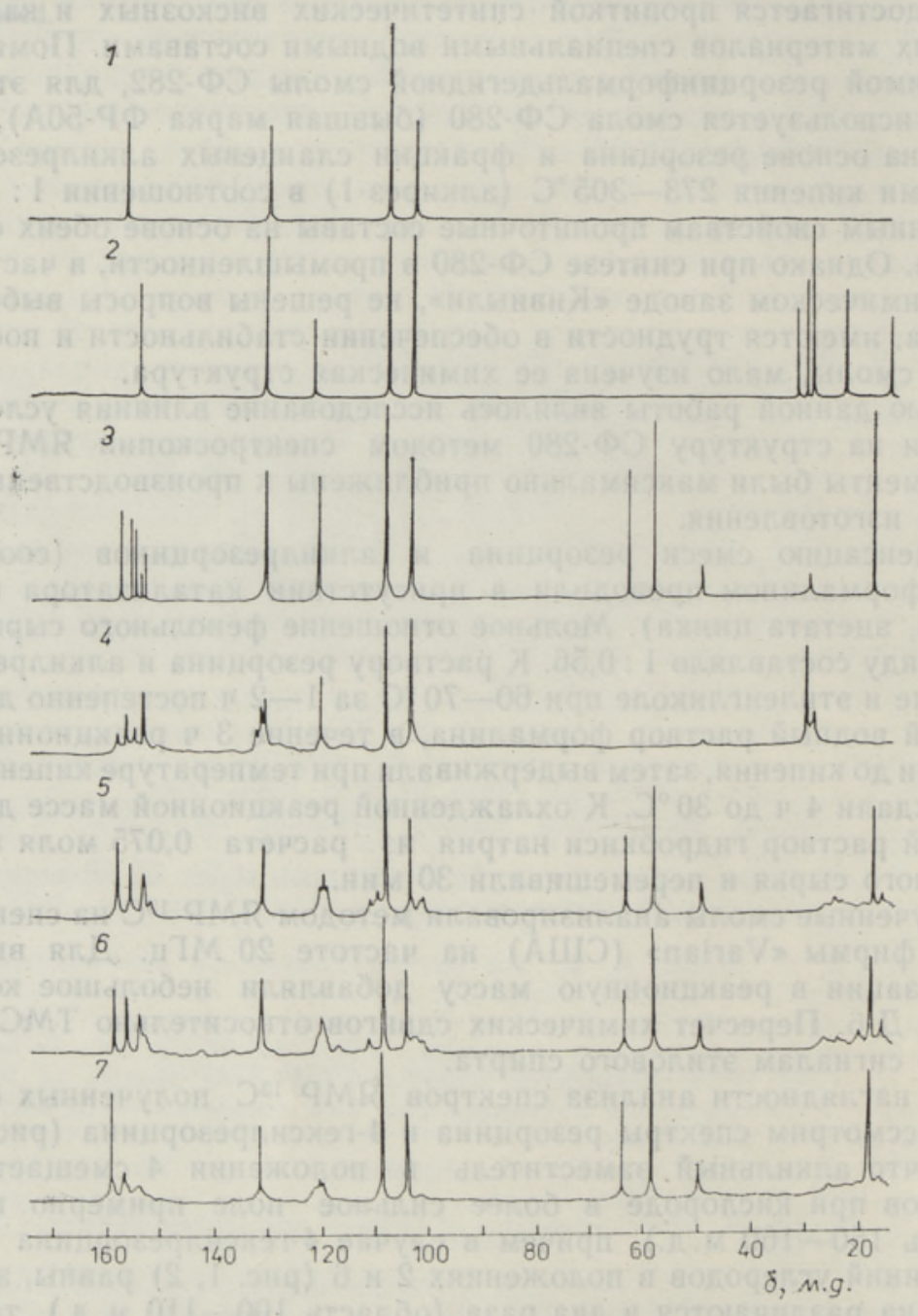

Рис. 1. Спектры ЯМР ${ }^{19} \mathrm{C}$ резорцина (1), 4-гексилрезорцина (2), фенолформальдегидной смолы на основе резорцина в спиртовой (3) и водной (4) средах, смолы СФ-280, полученной в присутствии уксусной кислоты (5) или ацетата цинка $(6)$, промышленной смолы СФ-280 (7). 
Во всех случаях конденсация идет главным образом в положениях 4 и 6 с образованием ди-, три- и тетрамеров. Резкое различение интенсивностей линий в области 100-110 м.д. и наличие сигнала 159 м.д. (рис, 1, 5,6 ) показывают, что реакция идет в основном с алкилрезорцинами, а бо́льшая часть резорцина не вступает в реакцию.

Влияние алкильных заместителей на распределение электронной плотности в фенолах можно оценить по результатам квантовохимических расчетов $\left[{ }^{4}\right]$ :

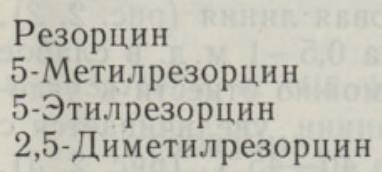

$\begin{array}{rr}\mathrm{C}_{2} & \mathrm{C}_{4}, \mathrm{C}_{6} \\ -0,106 & -0,087 \\ -0,131 & -0,106 \\ -0,119 & -0,110 \\ - & -0,107\end{array}$

Электронная плотность на $\mathrm{C}_{4}, \mathrm{C}_{6}$ резорцина примерно на $20 \%$ ниже, чем на тех же атомах его алкильных производных, что и является вероятной причиной пониженной реакционной способности резорцина.

Следует отметить, что хотя на $\mathrm{C}_{2}$ у всех фенолов наибольшая электронная плотность, конденсация по этому углероду идет незначительно. Это, вероятнее всего, можно объяснить блокированием $\mathrm{C}_{2}$ протонами гидроксильных групп. Спектр ЯМР ${ }^{13} \mathrm{C}$ промышленной смолы СФ-280

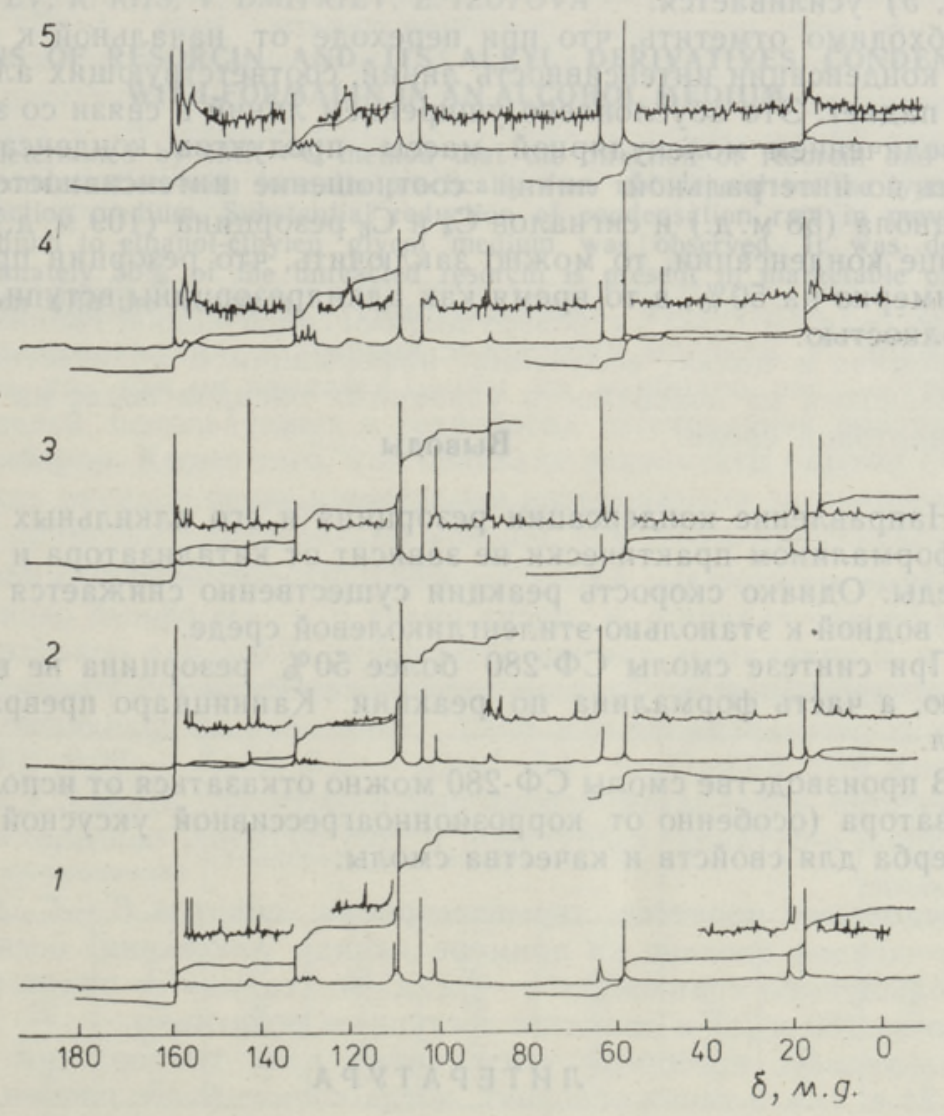

Рис. 2. Спектры ЯМР ${ }^{13} \mathrm{C}$ реакционной массы на различных стадиях получения смолы СФ-280: нсходная смесь фенолов в спиртовой среде $(1)$, после добавления формалина (2), после нагревания до $40-45^{\circ} \mathrm{C}(3)$, после кипячения при $90-93^{\circ} \mathrm{C}(4)$, после конденсации в щелочной среде (5). 
(рис. 1, 7) имеет те же линии, что и спектры смол, полученных в лабора торных условиях. Следовательно, большое количество непрореагировавшего резорцина имеется и в пробе промышленной смолы СФ-280.

Для уточнения хода конденсации смеси резорцина и его алкильных производных с формалином снимали спектры ЯМР ${ }^{13} \mathrm{C}$ реакционной массы после каждой стадии реакции. В спектре исходной смеси фенолов (рис. 2,1 ) заметны все характерные сигналы резорцина, 5-метил-, 2,5диметил- и 5-этилрезорцинов, а также высших гомологов и растворителей. После добавления в реакционную массу формалина (его сигналы 85-90 м.д.) в спектре ЯМР ${ }^{13} \mathrm{C}$ появляется новая линия (рис. 2,2 ), сдвинутая относительно сигнала этиленгликоля на $0,5-1$ м. д. в слабое поле (область 63-65 м.д.). Вероятнее всего, ее можно отнести к углероду метилольных групп. Интенсивность этой линии увеличивается с возрастанием температуры реакционной массы до $40-45^{\circ} \mathrm{C}$ (рис. 2,3 ). После кипячения реакционной смеси сигналы метилольных групп исчезают (рис. 2,4 ), однако в спектре остается сигнал непрореагировавшего формальдегида $(85-90$ м. д.) и появляется новый около 50 м. д., который соответствует (по химическому сдвигу) углероду метилового спирта. При добавлении метилового спирта в реакционную массу интенсивность сигнала (50 м.д.) в спектре ЯМР ${ }^{13} \mathrm{C}$ возрастает. Образование метанола объясняется протеканием реакции Канниццаро (самоокисления-самовосстановления), которая характерна для альдегидов в щелочной среде. После конденсации в щелочной среде интенсивность линии метанола (рис. 2, 5) усиливается.

Необходимо отметить, что при переходе от начальной к последней стадии конденсации интенсивность линий, соответствующих алкилрезорцинам, падает. Это обусловлено уширением линий в связи со значительным увеличением молекулярной массы продуктов конденсации. Если сравнить по интегральной линии соотношение интенсивностей сигнала $\mathrm{CH}_{2}$ этанола (58 м.д.) и сигналов $\mathrm{C}_{4}$ и $\mathrm{C}_{6}$ резорцина (109 м.д.) в начале и в конце конденсации, то можно заключить, что резорцин прореагировал примерно на $50 \%$, в то время как алкилрезорцины вступили в реакцию полностью.

\section{Выводы}

1. Направление конденсации резорцина и его алкильных производных с формалином практически не зависит от катализатора и реакционной среды. Однако скорость реакции существенно снижается при переходе от водной-к этанольно-этиленгликолевой среде.

2. При синтезе смолы СФ-280 более $50 \%$ резорцина не вступает в реакцию, а часть формалина по реакции Канниццаро превращается в метанол.

3. В производстве смолы СФ-280 можно отказаться от использования катализатора (особенно от коррозионноагрессивной уксусной кислоты) без ущерба для свойств и качества смолы.

\section{Л ИТЕ РА Т У Р А}

1. Кийс K. Э., Смирнова Н. А., Рятсеп А. Я. О технологическом режиме синтеза смолы СФ-280. - Горючие сланцы (ЭстНИИНТИ), 1977, № 8, 21-25.

2. Prtcen A. Я., Кийс К. Э., Смирнова Н. А. Синтетические смолы для шинной промышленности на основе алкилрезорцинов. - Горючие сланцы (ЭстНИИНТИ), 1977, № 2, 16-18. 
3. Липпмаа Х. В., Оливсон А. И. Исследование структуры фенолформальдегидных смол спектроскопическими методами. - Тр. Таллинск. политехн. ин-та, 1980, № 491, $45-53$.

4. Васильев В. В., Комаров В. Я., Веткова Л. Б., Ионин Б. И. Химические сдвиги углерода-13 одно- и двухатомных фенолов. - Ж. орг. хим., 1982, 52, вып. 3, 524528.

Научно-исследовательский институт сланцев

Поступила в редакцию

7/IV 1986

\section{VASSILJEV, K. KIIS, V. DMITRIJEV, J. IZOTOVA \\ RESORTSIINI JA TEMA ALKUOLDERIVAATIDE NING FORMALIINI KONDENSATSIOONI SEADUSPÄRASUSED ALKOHOLKESKKONNAS}

${ }^{13} \mathrm{C}$ TMR meetodil on kindlaks tehtud, et resortsiini ja tema alküülderivaatide ning formaliini kondensatsiooni suund praktiliselt ei sõltu katalüsaatorist ega reaktsiooni keskkonnast. On näidatud, et kondensatsiooni kiirus alaneb tunduvalt üieminekul vesikeskkonnast etanool-etüleenglükoolkeskkonda. On kindlaks tehtud, et kaubastatav vaik SF-280 sisaldab umbes $50 \%$ reageerimata resortsiini arvestatuna lähtetoorainele.

\section{VASSILYEV, K. KIIS, V. DMITRIEV, E. IZOTOVA}

\section{DIRECTIONS OF RESORCIN AND ITS ALKYL DERIVATIVES CONDENSATION WITH FORMALIN IN AN ALCOHOL MEDIUM}

It was determined by NMR ${ }^{13} \mathrm{C}$ method that the direction of resorcin and its alkyl derivatives condensation with formalin practically does not depend on the type of catalyst and reaction medium. Substantial reduction of condensation rate in moving from aqueous medium to ethanol-ethylen glycol medium was observed. It was determined that approximately $50 \%$ of the unreacted resorcin is present in marketable oil SF-280 in comparison with the feedstock. 